\title{
Reconstructing Pre-Service Teacher Perceptions through a Service-Learning Project at a Homeless Shelter
}

\author{
Valerie Zelenka \\ ${ }^{1}$ Department of Teacher Education, Fort Hays State University, Hays, USA \\ Correspondence: Valerie Zelenka, Assistant Professor and special education program coordinator, Department of \\ Teacher Education, Fort Hays State University, 600 Park Street, Hays, KS, 67601-4099, USA.
}

Received: May 25, 2016

doi:10.5430/irhe.v1n2p143
Accepted: June 7, 2016

Online Published: July 20, 2016

URL: http://dx.doi.org/10.5430/irhe.v1n2p143

\begin{abstract}
With a purpose of reconstructing pre-service teachers' perceptions about homelessness, an elementary education professor implements a service-learning field experience at the city's homeless shelter for families. For this qualitative study, I collected data for six semesters and measured the changes in pre-service teachers' perceptions, attitudes, and beliefs about working with children and families experiencing homelessness. At the beginning of this study, the pre-service teachers expressed various concerns about tutoring children at a homeless shelter. Regardless of their initial concerns, however, the pre-service teachers reported this service-learning project was a valuable learning experience. Recommendations include implementing service-learning with all pre-service teachers early and often within teacher preparation programs. These experiences should focus on both formal and informal learning and should allow for pre-service teachers to work closely with struggling at-risk students.
\end{abstract}

Keywords: service-learning, homeless children, pre-service teachers, field experiences

\section{Introduction to Issues}

Each night in the United States, approximately 1.5 million children do not have a home to call their own (National Center on Family Homelessness, 2012). In the past few years, the number of children and families experiencing homelessness and extreme poverty has increased significantly across the nation. For homeless children, residence instability, frequent school changes, excessive absenteeism, and transportation issues present major educational challenges beyond those experienced by housed peers (Books, 2004; Powers-Costello \& Swick, 2011; Sinatra, 2007). Rubin et al. (1996) documented that $75 \%$ of U.S. homeless children performed below grade level in reading and teachers may not have the necessary experience, attitudes, and beliefs to teach these students, thereby further delaying their academic achievement (Books, 2004).

Subsequently, Powers-Costello and Swick (2011) reported teachers can have a profound and positive effect on both the daily lives and the futures of homeless children. They maintained teachers' perceptions-positive or negative - influence their interactions with children and their families and can have dramatic and long-lasting effects on the lives of the homeless children. Milenkiewicz (2005) found teachers' perceptions about homelessness - student abilities and the importance parents place on education-were based on experience. Milenkiewicz reported, in most cases, negative perceptions - influenced by stereotypical images (e.g. homeless children being low functioning and having behavior problems and parents being lazy and irresponsible) - are the direct result of lack of experience working with homeless families. However, when pre-service teachers have the opportunity to work with homeless children and their families during a university-supervised and mentored internship, they develop the necessary skills, attitudes, and beliefs to teach homeless children (Sinatra, 2007).

Thus, teacher education programs should provide pre-service teachers with coursework in specialized academic interventions, an authentic field experience, and a supportive university mentorship so they can develop specialized skills and optimistic perceptions of children and families who face homelessness and extreme hardship (Books, 2004; Powers-Costello \& Swick, 2011; Sinatra, 2007; Steinke \& Fitch, 2014). This article addresses how the perceptions of elementary education pre-service teachers was transformed after enrolling in literacy tutoring internships for kindergarten through fifth grade students at a homeless shelter. 


\section{Purpose of Study}

Service-learning is not a contemporary idea. John Dewey (1938) stated that education and learning are a social and interactive process, so educational institutions are the framework through which social reform can and should take place. In addition, he believed that students thrive in learning environments where they experience and apply the curriculum. He argued that the purpose of education should not revolve around the acquisition of a pre-determined set of skills but rather the realization of one's full potential and the ability to use those skills for the greater good. Dewey's work influenced the implementation of present-day service-learning, an approach that connects traditional classroom experience with real-life lessons that come through service to the community.

A great deal of research has highlighted the benefits of integrating relevant service-learning opportunities with university coursework (Arrington, 2014; McDonald \& Dominguez, 2015; Peterson \& Bruster, 2014; Steinke \& Fitch, 2014). Unfortunately, Smagorinsky, Cook, Moore, Jackson, and Fry (2004) found, for many pre-service teachers, an apparent great divide exists between their university preparation and what they experience in the classroom after graduation. For this reason, teacher-preparation programs must provide undergraduate education majors with university coursework and relevant service-learning field experiences that provide them opportunity to grow in knowledge, character, problem-solving skills, and understanding of civic responsibility - the foundation of an effective teacher (McDonald \& Dominguez, 2015; Powers-Castello \& Swick, 2011; Sinatra, 2007; Steinke \& Fitch, 2014).

A thorough review of research revealed limited investigation of the issue of teacher preparation in working with children and families experiencing homelessness and extreme hardship and stress. The present study addresses this gap by presenting qualitative data concerning how providing (a) an authentic service-learning field experience at a homeless shelter, (b) on-site mentorship by university faculty, and (c) relevant coursework in assessment and research-based intervention strategies helped to transform the perceptions, attitudes, and beliefs of pre-service teachers.

\section{Theoretical Framework}

Reconstructing pre-service teacher perceptions, attitudes, and beliefs about homeless children and their families is grounded in legitimate peripheral participation theory (Lave \& Wenger, 1991). Lave and Wenger (1991) based this theory on the belief that learning is social in nature, so it must be integrated into a community of practice for learning to occur. This theory is based on case studies of how novice practitioners learn in various occupational groups not characterized by formal training. Instead, training occurs within the learning situation (e.g. butchers in grocery stores). However, by comparison, legitimate peripheral participation theory is broader and more complex than the structure of the usual apprenticeship. It is a transitory concept - a bridge - through which concepts are taught in a formal learning environment (university classroom) and then applied in the context of a real-world situation (field experience internship). One of the principal effects of this theory is that it facilitates a transfer of learning to new situations in the context of a deeper understanding. This transfer occurs as the novice practitioners begin to understand the broader conditions to which their own efforts contribute (Lave \& Wenger, 1991).

In this study, pre-service teachers tutored kindergarten through fifth grade struggling at-risk children at a city's homeless shelter for families. The pre-service teachers enrolled in Corrections of Reading Problems were to student teach the following semester in one of the three public schools that serve the children living at the shelter. The knowledge and experience gained from interacting with others concerning this experience-peers, the university mentor, the staff at the shelter, the children, and their parents - as well as the learning gained through reflection on this experience enabled reconstruction of unfounded beliefs and perceptions to redefine the pre-service teachers' identities as student teachers and future teachers of homeless children.

\section{Methodology}

\subsection{Participants and the Service-Learning Field Experience}

The pre-service teachers in this study were undergraduate elementary education students at a private liberal arts university in the Midwest. Students were enrolled in a one-semester, three-credit lecture course - Correction of Reading Problems - and a corresponding one-credit internship. These two 16-week courses are taught by the same university professor and are taken concurrently the semester before student teaching. Over a period of six semesters, data detailing the perceptions of 148 pre-service teachers were collected. Of the 148 pre-service teachers, 129 were female, and 19 were male; one of the pre-service teachers was African-American, one was Hispanic, and the remaining 146 were Caucasian. 
The purpose of the Correction of Reading Problems Internship is to provide pre-service teachers with an opportunity to administer reading assessments, develop a reading intervention plan, and provide research-based reading intervention strategies to K-5 readers. Previously, the internship was held at the university education lab site, which served children of the university faculty and students. However, for this study, this service-learning field experience occurred at the city's homeless shelter for families. During this study, pre-service teachers met the same course requirements as students interning at the education lab; in addition, they gained experience working with children and families experiencing homelessness, extreme poverty, and stress. While improving the reading achievement of the homeless children was welcomed, it was not the purpose of this study. Therefore, data concerning children's reading levels were not collected for this study.

Immediately before the internship began, the pre-service teachers and university professor toured the homeless shelter and met with the director. Flyers informing parents about the tutoring program were distributed at the shelter. Parents registered their children for the tutoring program and received "fresh start points" for each session their child attended. "Fresh start points" are allocated by the shelter coordinator each time parents attended a workshop offered at the shelter. Parents then redeemed the points for household items once permanent housing was secured.

During the first four weeks, pre-service teachers received instruction on administering various formal and informal reading assessments and creating individualized reading intervention plans based on the analyses of assessment data. In addition, pre-service teachers explored how to select and administer research-based reading intervention strategies based on children's individual strengths and instructional needs in relation to the five elements of reading instruction: phonemic awareness, phonics, fluency, vocabulary, and comprehension. The 5th week of the semester, pre-service teachers, accompanied by their university professor, began the internship tutoring children at the homeless shelter. This service-learning field experience project was held on Tuesdays and Thursdays from 6:00 p.m. to 7:00 p.m.

\subsection{Data Collection and Analysis}

Data for this study were collected from analyses of preprogram and postprogram anonymous evaluations written by the pre-service teachers regarding their semester-long work tutoring homeless children. The purpose of the evaluations was to gather information regarding the pre-service teachers' (a) perceptions, attitudes, and beliefs about homeless children and their families and (b) whether the perceptions, attitudes, and beliefs changed (either positively or negatively) after the experience of working with the homeless. Written evaluations were collected the first and last weeks of the semester. In addition, the university professor kept a journal of anecdotal notes taken during each tutoring session at the shelter, as well as the questions and comments pre-service teachers made during on-campus lectures.

Course requirements for all pre-service teachers included case-study portfolios documenting their internship experiences tutoring a homeless child or a small group of homeless children. One section of this portfolio contained the pre-service teacher's personal reflections on each tutoring session. At the end of the semester, these data, along with the preprogram and postprogram anonymous evaluations, and the professor's journal were analyzed and coded to identify common themes.

\section{Results: Pre-Service Teachers Perceptions, Attitudes, and Beliefs}

\subsection{Prior to the Service-Learning Experience}

None of the pre-service teachers involved in this study reported personally knowing anyone who had experienced homelessness. In addition, they revealed that they had little awareness of homeless shelters. Surprisingly, most were unaware that the homeless shelter for families was three blocks from campus and, at full capacity, could house 105 families. In general, the pre-service teachers indicated they were interested in helping children in need; however, most of them expressed concern that the tutoring would take place in the evening at the homeless shelter. A few of them also expressed a concern about the facilities being clean and safe.

The pre-service teachers noted they were unsure that they would be able to make personal connections with their respective homeless students, and they doubted their ability to help the students improve their reading skills because these children were experiencing extreme stress and hardship. In addition, a few of the pre-service teachers admitted they believed the homeless children may have limited cognitive abilities and efforts to improve their literacy development was unlikely. Overall, the pre-service teachers were interested in helping at-risk children; however, they were also apprehensive that tutoring children at the homeless shelter would be a successful experience. 


\subsection{During the Service-Learning Experience}

Throughout the semester, following each tutoring session after the children had left the room, the pre-service teachers reviewed the evening - sharing successes and concerns with their peers and the university professor. In addition, the first 15 minutes of each on-campus lecture class was devoted to specific topics, questions, and concerns generated during the previous tutoring session. Both times were intended to be informal in nature and to allow pre-service teachers the opportunity to ask questions about various topics (i.e., instructional strategies; issues related to behavior, health, social-emotional well-being; and so on.).

Pre-service teachers were also encouraged to meet with the university professor privately with confidential concerns regarding their tutoring experiences. On one such occasion, a concern of child endangerment was shared with the professor, who then filed a report with the shelter and the department of social services. This concern was substantiated, and a family intervention plan was implemented by the family's social worker. During the six semesters of data collection, this was the only incident of concern.

Regarding lesson planning, the pre-service teachers provided a detailed reading-intervention lesson plan to the university professor a week in advance of each tutoring session. Lesson plans reviewed the prior skills taught, materials used, and new skills introduced, as well as a detailed reflection on each tutoring session. All pre-service teachers completed this requirement, making for a rich and meaningful analysis of their perceptions, attitudes, and beliefs during this stage of data collection.

\subsection{After the Service-Learning Experience}

Upon completion of the tutoring experience, all but one pre-service teacher expressed sincere gratitude for the experience of working at the homeless shelter. The pre-service teacher who did not enjoy the experience stated she felt uncomfortable because parents were seated around the perimeter of the room where the tutoring took place. They could listen to her instruction, a situation she found uncomfortable and caused her distress. The other 147 pre-service teachers stated a desire to continue to work with children at the shelter because of the connection they made with their students and the many positive experiences they shared.

At the end of the course, pre-service teachers were asked to discuss their experiences working at the homeless shelter and whether they believed this was a valuable experience that should continue to be offered to all pre-service teachers. Students were given the opportunity to share any comment or information regarding their experiences during this internship.

The data, collected in the form of anonymous written statements, conveyed the pre-service teachers' thoughts:

Even though the practicum was tough, I felt that it was a very worthwhile experience. It took us out of our comfort zone and showed us the harsh reality some students face. It was often uncomfortable, but sometimes we need discomfort to help us to grow. Every education major should have this experience!

I liked the shelter experience. Actually, I loved it. I felt that it was a great opportunity for the children, but I also felt that it was very beneficial to me. It gave me an opportunity to see that the kids that live at the shelter are just kids. I also feel that we need experiences working with the students that don't have the "typical" home life so that we are better prepared to have these children in our classrooms.

Another unanticipated finding came in a thank-you note from a social worker employed at the homeless shelter.

Most of the adults in this environment have interactions only with other adults in the same situation, which perpetuates their despair and feelings of helplessness. However, since some of the undergraduate students were adult (nontraditional) college students; as a result, they saw other adults-with families and challenges-making positive changes in their lives. Your students were great role models for both the children and their parents. Thank you for your work!

\section{Limitations}

Several limitations of this study should be considered when interpreting and applying the results. First, although this course is offered as an undergraduate course, it is not open to all undergraduate students. The undergraduate students enrolled in this course are pre-service teachers. Therefore, these demographics may skew the results of the study because the undergraduate candidates who enrolled in the course - Corrections of Reading Problems - already had a desire to work with and help at-risk students. If undergraduate participants not studying teacher education had participated, the pre-tutoring and post-tutoring feedback and overall experiences of the undergraduate participants may have been different. Second, the small number of participants in this study does not allow conclusions to be generalized across all tutoring situations. 
Third, all the data collected from the undergraduate participants were self-reported. No data were collected regarding the homeless children's achievement post-tutoring, so conclusions regarding the effectiveness of this study is based solely on the self-reports of pre-service teachers concerning changes in their perceptions, attitudes, and beliefs about working with homeless children. Tracking the reading achievement of the homeless children was not the purpose of this study. Finally, the author of this article served as both the instructor and faculty mentor for this course; therefore, the researcher's status and enthusiasm for this project may have influenced changes in the participants' beliefs and perceptions. However, the data collected from the undergraduate participants were in the form of anonymous self-reporting, so this last issue is not considered a major limitation.

\section{Discussion and Implications}

The purpose of this research was twofold. First, it was to determine whether and how pre-service teachers' perceptions, attitudes, and beliefs about homeless children and families changed after tutoring K-5th grade struggling readers at a homeless shelter. Second, it was to use these findings to develop suggestions about how teacher educators can facilitate pre-service teachers' learning by incorporating nontraditional service-learning field experiences to better prepare them for the challenges they will face when working with children and families experiencing homelessness and extreme hardship and stress.

\subsection{Implications for Pre-Service Teachers}

The data collected from the self-reported anonymous surveys and reflections indicated the pre-service teachers in this study changed their perceptions, attitudes, and beliefs about working with homeless children and their families. These beliefs changed as a direct result of this tutoring experience. At the beginning of this study, some of the pre-service teachers expressed concern about their ability to help homeless children make progress in reading. Some were also concerned with their ability to make personal connections with the homeless children and their families. Similar to the participants in a study by Friedland and Truscott (2005), pre-service teachers believed developing personal connections with students and their families was equally as important as teaching children reading skills.

Regardless of their initial concerns, however, the pre-service teachers in this study reported seeing positive changes in their students over time. Collectively, they also revealed that being part of the learning process and working with homeless children was a valuable learning experience. Data also indicated these pre-service teachers embraced working with the parents and felt as though the parents appreciated their efforts to help the children. Some pre-service teachers found it surprising that the parents expressed a sincere concern about their children's academic progress and asked for advice on how they could support their children's development.

\subsection{Implications for Teacher Educators}

According to the findings of this research, as well as related research (Arrington, 2014; McDonald \& Dominguez, 2015; Peterson \& Bruster, 2014; Powers-Castello \& Swick, 2011; Sinatra, 2007; Steinke \& Fitch, 2014), pre-service teachers experience many benefits from working in a service-learning field experience project. Teacher educators, as well as coordinators of teacher education programs, need to be aware of these benefits and implement service-learning in university field experiences. Given the research and my own experiences working with pre-service teachers, I suggest that service-learning field experiences should: (1) occur early and often within the teacher preparation program; (2) focus on both formal and informal learning; and (3) allow pre-service teachers to work closely with struggling at-risk students.

Service-learning field experiences should occur early and often within the teacher preparation program. When developing outlines for programs, in general, and courses, specifically, teacher educators and program coordinators should plan for pre-service teachers to have service-learning field experiences with students early in the program (i.e., when entering teacher education) and early in each methods course (i.e., reading, language arts, math, science). That is, the field experience should focus on the application of the content of the course. Whether the instruction is with a whole class, with a small group, or one-on-one, pre-service teachers will be able immediately to apply the knowledge they have acquired in the university classroom to their work with students, helping to reinforce and enhance their developing skills.

Further, by beginning service-learning experiences early in their program, pre-service teachers will have more opportunities to make connections with students. In addition, they will become aware of and acquire new teaching and behavior-management skills and become more confident in those skills (Allor, Cheek Jr., Smith, \& Schorzman, 2006; Arrington, 2014). All of these were concerns the pre-service teachers reported at the beginning of this study.

Service-learning experiences should focus on both formal and informal learning. Formal learning experiences - those in which the pre-service teachers have a specific task to perform, such as implementing a reading assessment, monitored by a university supervisor or cooperating teacher-are important because they offer the 
experience of applying the knowledge presented in their university coursework. Such formal experiences may increase the pre-service teachers' confidence in carrying out the responsibilities of a teacher (Arrington, 2014; Steinke \& Fitch, 2014).

Informal learning experiences - those in which the focus is on the pre-service teacher observing and spending time interacting with students and sometimes the classroom teacher-may offer many of the same benefits as formal learning experiences. In addition, these types of experiences offer pre-service teachers the chance to make personal connections with students. Pre-service teachers in this study voiced concerns about making connections with students. Teacher educators should acknowledge and address this concern by arranging experiences that can serve to alleviate it. Only when this concern is addressed should university instruction focus on acquiring and refining teaching skills. When pre-service teachers are engaged in early service-learning field experiences, they have the opportunity to become more comfortable interacting with students before assuming the role of teacher.

Service-learning experiences should allow pre-service teachers to work closely with struggling at-risk students. In working with pre-service teachers at various stages in their teacher preparation programs, I have noticed they are often unaware of their responsibility to work with struggling at-risk students. They often think there is someone else (i.e., a special education teacher, a school counselor, or a social worker) who is responsible for these students. Often, pre-service teachers do not understand students in their classrooms will be working at different levels and the teachers are responsible for the students' instruction. However, when pre-service teachers have the opportunity to work with struggling at-risk students, they begin to take responsibility for the students' success, thus helping to build the pre-service teachers' confidence.

\section{References}

Arrington, N. M. (2014). Enriching teaching and learning in a teacher education course through a field experience choice assignment in service-learning. Journal of Education and Human Development, 3(2), 991-1016.

Books, S. (2004). Poverty and schooling in the U.S.: Contexts and consequences. Mahwah, NJ: Erlbaum.

Dewy, J. (1938). Experience and education. New York: NY: Collier MacMillan.

Fitzgerald, J. (2001). Can minimally trained college student volunteers help young at-risk children to read better? Reading Research Quarterly, 36(1), 28-46. http://dx.doi.org/10.1598/RRQ.36.1.2

Friedland, E. S., \& Truscott, D. M. (2005). Building awareness and commitment of middle school students through literacy tutoring. Journal of Adolescent \& Adult Literacy, 48(7), 550-562. http://dx.doi.org/10.1598/JAAL.48.7.2

Lave, J., \& Wenger, E. (1991). Situated learning: Legitimate peripheral participation. Cambridge, UK: Cambridge University Press. http://dx.doi.org/10.1017/CBO9780511815355

McDonald, J., \& Dominguez, L. (2015). Developing university and community partnerships: A critical piece of successful service learning. Journal of College Science Teaching, 44(3), 52-56. http://dx.doi.org/10.2505/4/jcst15_044_03_52

Milenkiewicz, M. (2005). Colorado educators study of homeless and highly mobile students. Denver, CO: Colorado Department of Education.

National Center on Family Homelessness. (2012). The characteristics and needs of families experiencing homelessness. Retrieved from http://www.familyhomelessness.org/q=node/4

Peterson, B. R., \& Bruster, B. G. (2014). Inquiry into the reflective practice of teacher candidates. International Journal of Education and Social Science, 1(3), 140-154.

Powers-Costello, B., \& Swick, K. J. (2011). Transforming teacher constructs of homeless children and families. Early Childhood Education Journal, 36(3), 207-212. http://dx.doi.org/10.1007/s10643-011-0455-z

Rubin, D. H., Erickson, C. J., San Agustin, M., Cleary, S. D., Allen, J. K., \& Cohen, P. (1996). Cognitive and academic functioning of homeless children compared with housed children. Pediatrics, 97(3), 289-294.

Sinatra, R. (2007). Literacy success with homeless children. The Journal of At-Risk Issues, 13(2), 1-9.

Smagorinsky, P., Cook, L. S., Moore, C., Jackson, A. Y., \& Fry, P. G. (2004). Tensions in learning to teach: Accommodation and the development of a teaching identity. Journal of Teacher Education, 55(1), 8-23. http://dx.doi.org/10.1177/0022487103260067

Steinke, P., \& Fitch, P. (2014). Using goal-based learning to understand why service-learning improves cognitive outcomes. Currents in Teaching \& Learning, 7(1), 50-63. 